\title{
PENERAPAN REGRESI POISSON TERHADAP PELUANG LULUS DENGAN MASA STUDI MAHASISWA KURANG DARI EMPAT TAHUN DI FMIPA UNSRAT
}

\author{
Petrus Togi Heriyanto Pangaribuan ${ }^{1}$, Hanny A. H Komalig ${ }^{1}$,Nelson Nainggolan ${ }^{1}$ \\ ${ }^{1}$ Program Studi Matematika, Fakultas Matematika dan Ilmu Pengetahuan Alam, \\ Universitas Sam Ratulangi Manado \\ e-mail : Petrus_togi@yahoo.com;hanoy07@gmail.com;n-nelson@unsrat.ac.id
}

\begin{abstract}
ABSTRAK
Belajar merupakan hak setiap orang, tetapi kegiatan belajar di suatu perguruan tinggi merupakan suatu hak istimewa karena hanya orang yang memenuhi syarat saja yang berhak belajar di lembaga pendidikan tersebut. Faktor-faktor yang mempengaruhi peluang lulus di bawah empat tahun di FMIPA unsrat bisa berasal dari beberapa faktor internal dan eksternal. Penelitian ini dilakukan selam 4 bulan sejak bulan November 2018 sampai bulan Maret 2019. Tujuan dari penelitian ini adalah menentukan peluang lulus dengan masa studi mahasiswa di bawah empat tahun di FMIPA Unsrat dan menentukan faktor-faktor yang signifikan terhadap peluang lulus dengan mahasiswa kurang dari empat tahun menggunakan regresi poisson. Dari hasil analisis pada penerapan regresi poisson terhadap peluang lulus dengan masa studi mahasiswa di FMIPA Unsrat dapat diperoleh kesimpulan bahwa variabel mengikuti dan aktif sebagai KSB (Ketua, Sekretaris, Bendahara ) $\left(\mathrm{X}_{2}\right)$ dan mengikuti dan sebagai perwakilan Unsrat pada ON MIPA $\left(\mathrm{X}_{3}\right)$ tidak berpengaruh secara signifikan terhadap peluang lulus dengan masa studi mahasiswa kurang dari empat tahun di FMIPA Unsrat dan untuk variabel IPK $\left(\mathrm{X}_{1}\right)$ berpengaruh terhadap model dan diperoleh model sebagai berikut : $\hat{\mu}=\exp \left(-3,828+1,072 \mathrm{X}_{1}\right)$
\end{abstract}

Kata kunci: Peluang, Regresi Poisson, FMIPA UNSRAT, maximum likelihood

\section{THE APPLICATION OF POISSON REGRESSION TO PROBABILITY OF LESS THAN GRADUATED AT FACULTY OF MATHEMATICS AND NATURAL SCIENCES SAM RATULANGI UNIVERSITY}

\begin{abstract}
Learning is the right of every people, but learning activities in a college are a privilege because only people who meet the requirements are entitled to study at the educational institution. Factors that influence the The probability of less than graduated at Faculty of Mathematics and Natural Sciences Sam Ratulangi University can come from several internal and external factors. The study was conducted for 4 months from November 2018 to March 2019. The probability of on time graduated at Faculty of Mathematics and Natural Sciences Sam Ratulangi University using poisson regression. From the results of the analysis on the application of Poisson regression The purpose of the study was to determine the probability of on time graduated at Faculty of Mathematics and Natural Sciences Sam Ratulangi University and to determine the factors which influence on it. The variable of involvement as $\mathrm{KSB}$ (Chair, Secretary and treasurer) $\left(\mathrm{X}_{2}\right)$ and member of delegation ON MIPA $\left(X_{3}\right)$ has no significant effect and for the GPA variable $\left(X_{1}\right)$ affects the model and the final model is obtained as follows: $\hat{\mu}=\exp \left(-3,828+1,072 \mathrm{X}_{1}\right)$
\end{abstract}

Keywords: Probability, Poisson Regression, FMIPA UNSRAT, maximum likelihood

Article History:

Received: July 4, 2019

Accepted: July 9, 2019

Published: July 9, 2019 


\section{PENDAHULUAN}

Pada dasarnya setiap perguruan tinggi berusaha semaksimal mungkin untuk meningkatkan kelulusan para mahasiswanya, baik secara kuantitas maupun kualitas. Secara kuantitas artinya jumlah mahasiswa yang masuk terdaftar sama dengan jumlah mahasiswa yang lulus, berarti tidak ada yang Drop Out (DO). Secara kualitas, diharapkan mahasiswa lulus dengan nilai Indeks Prestasi Kumulatif (IPK) maksimal dan tepat waktu, terdapat sejumlah hasil yang menunjukkan faktor-faktor yang memengaruhi peluang lulus kurang dari empat tahun. Di antara faktor-faktor tersebut, sebagian digunakan sebagai variabel penjelas dalam penelitian ini, diantaranya adalah faktor IPK, kegiatan organisasi dan menjabat sebagai KSB ( ketua , sekretaris dan bendahara ), mengikuti Olimpiade Sains dan menjadi utusan Unsrat. Penulis ketahui penelitian tentang analisis faktor-faktor yang mempengaruhi peluang lulus mahasiswa dengan masa studi kurang dari empat tahun di Fakultas Matematika dan Ilmu Pengetahuan Alam (FMIPA) yang menggunakan regresi poisson belum pernah dilakukan. Oleh karena itu, dalam tulisan ini disampaikan hasil penelitian tentang analisis faktor-faktor yang mempengaruhi peluang lulus mahasiswa dengan masa studi kurang dari empat tahun mahasiswa di FMIPA Unsrat dengan menggunakan regresi poisson.

\section{Regresi Poisson}

Model Regresi Poisson merupakan model regresi nonlinear yang digunakan untuk menganalisis data diskrit (count). Beberapa karakteristik dari percobaan yang mengikuti sebaran distribusi Poisson

1. Kejadian yang terjadi pada jumlah anggota populasi yang besar dengan probabilitas yang kecil (kejadian yang jarang terjadi)

2. Kejadian yang termasuk ke dalam counting process atau termasuk ke dalam lingkungan proses stokastik

3. Bergantung pada interval waktu tertentu

Model Regresi Poisson merupakan

Generalized Linear Model (GLM) yang data responnya diasumsikan berdistribusi Poisson. Model regresi Poisson diberikan sebagai berikut :

$$
\begin{aligned}
& y_{i} \sim \operatorname{Poisson}\left(\mu_{i}\right) \\
& \mu_{i}=\exp \left(x_{i}^{T} \beta\right)
\end{aligned}
$$

Maka,

$\operatorname{Ln}\left(\mu_{i}\right)=\beta_{0}+\beta_{1} x_{1 i}+\beta_{2} x_{2 i}+\ldots . .+\beta_{k} x_{k i}$

(1)

Dimana $: \beta_{0}, \beta_{1} \ldots, \beta_{k}=$ parameter $/$

koefisien regresi

$x_{1 i}, x_{2 i}, \ldots, x_{k i} \quad=$ konstanta yang

diketahui nilainya

\section{Penaksiran Parameter Regresi Poisson}

Metode MLE ( Maximum Likelihood)

adalah salah satu metode penaksiran parameter yang dapat digunakan untuk menaksir parameter suatu model yang diketahui distribusinya. Sebagaimana diketahui bahwa taksiran parameter melalui metode MLE adalah melakukan turunan parsial fungsi kemungkinan terhadap parameter yang akan ditaksir ( Cameron dan Trevedi, 1998).

\section{Pengujian Hipotesis}

Pengujian hipotesis dilakukan untuk melihat apakah variabel-variabel yang terdapat dalam model memiliki hubungan yang signifikan dengan variabel respon. Menurut Hosmer dan Lemeshow (2000), pengujian dapat dilakukan dengan uji serentak dan uji parsial.

Uji parsial dilakukan terhadap masing-masing variabel prediktor yang ada secara individual untuk melihat pengaruh masing-masing variabel prediktor terhadap nilai respon.

Statistik uji yang digunakan adalah :

$$
\mathrm{W}=\frac{B_{i}}{S E\left(\hat{B}_{j}\right)}
$$

Jika nilai $\mathrm{W}>Z_{a}$ atau $\mathrm{P}-$ value $<\alpha$ maka tolak $H_{0}$ artinya koefisien regresi tersebut signifikan ( Uyanto,2009).

Dalam metode regresi Poisson diasumsikan bahwa mean dan varian responnya sama. Namun adakalanya nilai varian lebih besar dari nilai mean (overdispersi) atau varian lebih kecil dari mean respon menyatakan bahwa overdispersi terjadi apabila nilai rasio antara varian dan mean lebih besar dari 2,5. (Agresti, A. 1990; Purhadi, 2013). 


\section{Ukuran Goodness of Fit Model Regresi Poisson}

Kleinbaum (1988) menjelaskan bahwa untuk melihat kesesuaiann model regresi poisson dapat digunakan ukuran goodness of fit yang disebut juga sebagai devian. Devian pada regresi poisson analog dengan SSE $=\sum_{i=1}^{n}\left(y_{i}-\hat{y}_{i}\right)^{2}$ pada regresi linear berganda ( multiple linear regression ).

Nilai devian model merupakan selisih antara nilai log likelihood model sederhana (tanpa melibatkan variabel prediktor) dan nilai log likelihood model yang lebih lengkap (dengan melibatkan variabel).

\section{Indeks Prestasi Kumulatif}

Indeks Prestasi Kumulatif yang selanjutnya disingkat IPK adalah angka prestasi akademik mahasiswa yang dihitung dari semua matakuliah untuk semua semester yang sudah diikuti oleh mahasiswa (Peraturan Rektor Unsrat No. 01/UN12/PP/2013). IPK dihitung dari semua matakuliah untuk semua semester yang sudah diikuti oleh mahasiswa dengan menggunakan rumus berikut :

$I P K=\Sigma(N . K) / \sum K$

\section{Keterangan}

$\mathrm{K}=$ besarnya bobot kredit matakuliah dari semua semester

$\mathrm{N}=$ nilai huruf setelah dikonversi ke bentuk bilangan

Penilaian hasil belajar program diploma, program sarjana, program magister, profesi, program spesialis, dan program doktor dinyatakan dengan huruf $\mathrm{A}, \mathrm{B}+, \mathrm{B}$, $\mathrm{C}+, \mathrm{C}, \mathrm{D}$, dan $\mathrm{E}$ yang masing -masing melalui nilai konversi bilangan $4 ; 3,5 ; 3,0$; 2,5; 2,0; 1,0; dan 0 (Peraturan Rektor Unsrat No. 01/UN12/PP/2013).

\section{Organisasi}

Organisasi merupakan suatu sistem yang saling berinteraksi dan bekerjasama dalam rangka mencapai tujuan bersama. Pencapaian tujuan organisasi bukan hanya untuk kepuasan individual, tetapi untuk kepuasan dan manfaat bersama-sama. Organisasi yang ada di Perguruan Tinggi seperti organisasi Kemahasiswaan. Adanya organisasi di Perguruan Tinggi diharapkan mampu meningkatkan kualitas ilmu pegetahuan, menambah pengalaman individu dan mampu bersaing di era globalisasi

\section{METODE PENELITIAN}

\section{Sumber Data}

Data yang digunakan dalam penelitian ini berasal dari data sekunder. Data sekunder berupa data yang di ambil di bagian kemahasiswaan FMIPA Universitas Sam Ratulangi Manado

\section{Waktu dan Tempat Penelitian}

Penelitian ini dilakukan pada bulan November 2018 sampai bulan Maret 2019 di Fakultas Matematika dan Ilmu Pengetahuan Alam Universitas Sam Ratulangi.

\section{Variabel Penelitian}

Variabel dalam penelitian ini adalah peluang lulus dengan masa studi mahasiswa dibawah empat tahun di Fmipa Unsrat. Peubah ini diamati sejak mahasiswa melakukan registrasi pertama, yaitu ketika pertama kali mereka tercatat sebagai mahasiswa di FMIPA Unsrat hingga mahasiswa tersebut berstatus kemudian lulus.

Variabel yang diduga mempengaruhi masa studi mahasiswa FMIPA Unsrat antara lain adalah :

1. $\operatorname{IPK}\left(\mathrm{X}_{1}\right)$

2. Mengikuti organisasi dan menjabat KSB ( Ketua, Sekretaris dan Bendahara) di Himpunan jurusan $\left(\mathrm{X}_{2}\right)$

3. Mengikuti lomba ON MIPA dan menjadi perwakilan Unsrat $\left(\mathrm{X}_{3}\right)$

\section{Metode Analisis}

Langkah-langkah yang dilakukan untuk menganilis data dalam penelitian ini adalah sebagai berikut :

1. Mendeskripsikan karakteristik penerapan regresi poisson terhadap pelang lulus dengan masa studi kurang dari empat tahun di Fmipa Unsrat.

2. Menyeleksi variabel penelitian untuk untuk melihat hubungan antara variabel Prediktor terhadap variabel respon.

3. Melakukan uji serentak dan uji parsial untuk mengetahui variabel yang berpengaruh signifikan. 
4. Menginterpretasikan peluang lulus dengan masa studi kurang dari empat tahun.

5. menyimpulkan suatu kasus dengan model regresi poisson yang telah diperoleh.

\section{HASIL DAN PEMBAHASAN}

\section{Gambaran Umum Data}

Data peluang lulus dengan masa studi dibawah empat tahun di FMIPA Unsrat pada Tahun 2015 - 2018 dari program studi : Matematika, Biologi, Kimia, Fisika dan Farmasi.

Pada penelitian ini akan dipaparkan mengenai statistika deskriptif dari faktorfaktor yang diduga berpengaruh terhadap peluang lulus kurang dari tahun mahasiswa di FMIPA Unsrat, mahasiswa yang lulus di bawah empat tahun di FMIPA Unsrat dari tahun 2015 - 2018 sebanyak 25 orang dengan IPK rata - rata 3,62, dengan nilai IPK maxsimum 3,98 dan nilai minimun 3,24 dengan nilai standar deviasi sebesar 0,23 untuk aktif berorganisasi untuk mahasiswa yang lulus kurang dari empat tahun di FMIPA Unsrat memiliki rata-rata 0,12 , sedangkan untuk yang mengikuti olimpiade sains memiliki rata-rata 0,20 . dapat dilihat bahwa data mahasiswa yang lulus di bawah empat tahun masih jarang terjadi pada tahun 2015-2018, hal ini bisa disebabkan oleh faktor dari IPK $\left(\mathrm{X}_{1}\right)$, aktif berorganisai di himpunan jurusan $\left(\mathrm{X}_{2}\right)$ dan mengikuti Olimpiade Nasional $\left(\mathrm{X}_{3}\right)$.

\section{Variabel $\mathrm{X}_{1}$ ( IPK)}

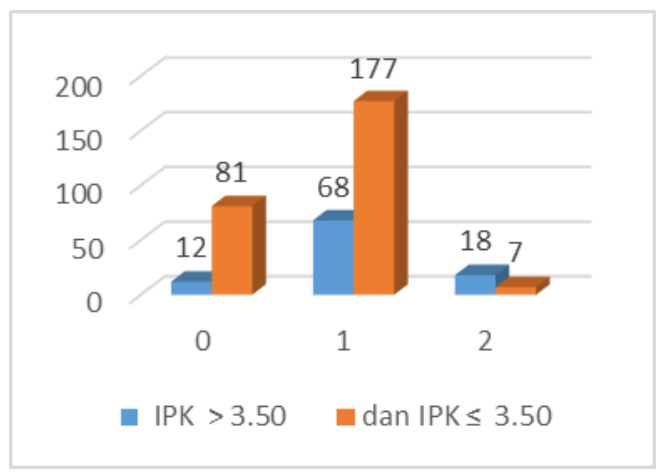

Gambar 2. Grafik IPK
Variabel $\left(\mathrm{X}_{2}\right)$ Indeks Prestasi Kumulatif (IPK), mahasiswa yang lulus pada Jurusan (Matematika, Biologi, kimia, fisika, dan farmasi) di FMIPA Unsrat dari tahun 2015 - 2018 dikategorikan menjadi 2 kategori yaitu IPK > 3,50 dan $\quad$ IPK $\leq$ 3,50 .

Dari 363 Mahasiswa yang lulus di Fmipa Unsrat pada 2015 - 2018 diperoleh data mahasiswa dengan IPK > 3,50 berjumlah 96 orang dan IPK $\leq 3,50$ berjumlah 267 orang. Untuk mahasiswa yang lulus kurang dari empat tahun yang memiliki IPK > 3,50 berjumlah 18 orang dan yang memiliki IPK $\leq 3,50$ berjumlah 7 orang, untuk mahasiswa yang $4 \leq$ lulus $\leq 5$ tahun yang memilikih IPK > 3,50 berjumlah 68 orang, sedangkan yang memiliki IPK $\leq 3,50$ berjumlah 177 orang dan untuk mahasiswa yang lulus > 5 tahun yang memiliki IPK > 3,50 berjumlah 12 orang sedangkan yang memiliki IPK $\leq 3,50$ berjumlah 81 orang.

\section{Variabel $\mathrm{X}_{2}$ ( Organisasi )}

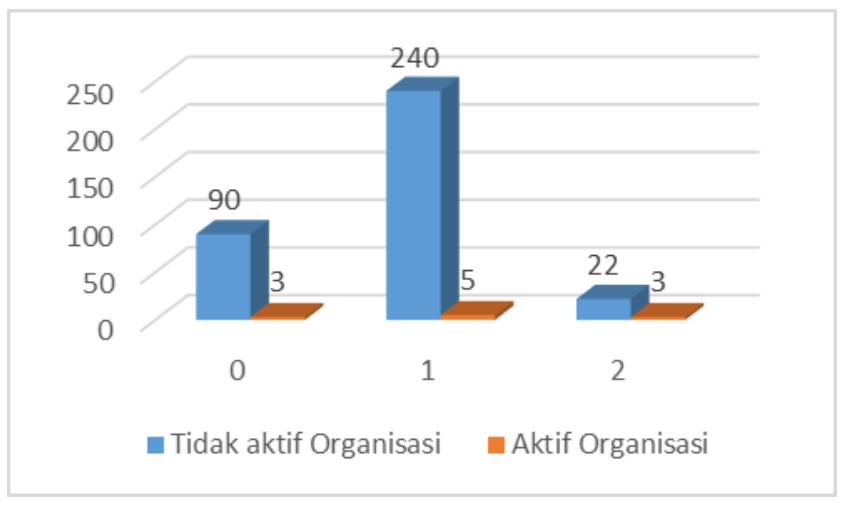

Gambar 3. Grafik Organisasi

Variabel $\left(\mathrm{X}_{2}\right), \quad$ kegiatan aktif Organisasi pada Himmaju ( Himpunan Mahasiswa Jurusan) dan menjabat KSB (Ketua, Bendahara, Sekretaris)

Mahasiswa FMIPA Unsrat yang telah lulus pada tahun 2015-2018 dikategorikan menjadi 2 yaitu aktif dan mejabat KSB (ketua, sekretaris dan bendahara) dan tidak aktif, dari data yang diambil pada lulusan tahun 2015 - 2018 diperoleh data mahasiswa yang aktif berorganisasi berjumlah 11 orang dan yang tidak aktif berjumlah 352 orang dan untuk mahasiswa yang aktif berorganisasi yang lulus < 4 tahun berjumlah 3 orang dan untuk yang tidak aktif berorganisasi sebanyak 22 
orang, sedangkan mahasiswa yang $4 \leq$ lulus $\leq 5$ tahun yang aktif berorganisasi sebanyak 5 orang dan yang tidak aktif berorganisasi sebanyak 240 orang dan mahasiswa yang lulus > 5 tahun yang aktif beroganisasi sebanyak 3 orang dan yang tidak aktif berorganisasi sebanyak 90 orang.

\section{Variabel $\mathrm{X}_{3}$ ( Olimpiade )}

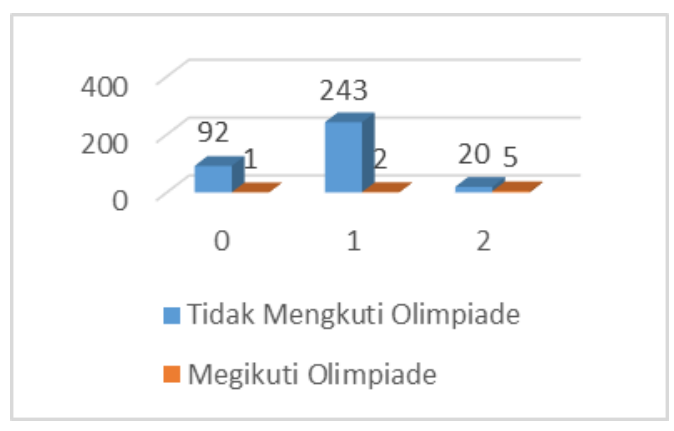

Gambar 4. Grafik Olimpiade

Variabel $\left(\mathrm{X}_{3}\right)$, kegiatan mengikuti Olimpiade dan pernah menjadi perwakilan di FMIPA Unsrat yang lulus pada tahun 20152018 dikategorikan menjadi 2 yaitu mengikuti dan sebagai perwakilan Unsrat pada Olimpiade Nasional dan tidak mengikuti dan tidak menjadi perwakilan Unsrat pada Olimpiade Nasional, dari data lulusan pada tahun 2015 - 2018 diperoleh data mahasiswa yang mengikuti dan sebagai perwakilan Unsrat pada Olimpiade Nasional berjumlah 11 orang dan yang tidak mengikuti serta tidak menjadi perwakilan Unsrat pada Olimpiade Nasional berjumlah 352 orang dan untuk mahasiswa yang mengikuti dan sebagai perwakilan Unsrat pada Olimpiade Nasional yang lulus $<4$ tahun berjumlah 5 orang, tidak mengikuti dan tidak menjadi perwakilan Unsrat pada Olimpiade Nasional sebanyak 20 orang, sedangkan mahasiswa yang $4 \leq$ lulus $\leq 5$ tahun mengikuti dan sebagai perwakilan Unsrat pada Olimpiade Nasional sebanyak 2 orang dan yang tidak mengikuti dan tidak menjadi perwakilan Unsrat pada Olimpiade Nasional sebanyak 243 orang, mahasiswa yang lulus > 5 tahun yang mengikuti dan sebagai perwakilan Unsrat pada Olimpiade Nasional sebanyak 0 orang dan yang Tidak mengikuti dan tidak menjadi perwakilan Unsrat pada Olimpiade Nasional sebanyak 93 orang

\section{Pemodelan Regresi Poisson}

Berikut ini adalah hasil pemodelan regresi poisson menggunkan aplikasi Minitab dengan variabel respon adalah jumlah mahasiswa yang lulus di FMIPA Unsrat Tahun 2015-

2018, variabel prediktor adalah IPK, Organisasi dan Olimpiade

\begin{tabular}{|c|c|c|c|c|c|}
\hline Source & $\mathrm{DF}$ & $\begin{array}{l}\text { Adj } \\
\text { Dev }\end{array}$ & $\begin{array}{l}\text { Adj } \\
\text { Mean }\end{array}$ & $\begin{array}{l}\text { Chi- } \\
\text { Square }\end{array}$ & $\begin{array}{l}\text { P- } \\
\text { Value }\end{array}$ \\
\hline Regression & 3 & 27,040 & 9,0133 & 27,04 & 0,000 \\
\hline $\mathrm{X} 1$ & 1 & 21,582 & 21,5816 & 21,58 & 0,000 \\
\hline $\mathrm{X} 2$ & 1 & 0,039 & 0,0390 & 0,04 & 0,844 \\
\hline X3 & 1 & 0,698 & 0,6978 & 0,70 & 0,404 \\
\hline Error & 359 & 164,657 & 0,4857 & & \\
\hline Total & 362 & 191,697 & & & \\
\hline \multicolumn{6}{|c|}{ Coefficients } \\
\hline \multicolumn{2}{|l|}{ Term } & Coef & \multicolumn{2}{|c|}{ SE Coef } & VIF \\
\hline \multirow{2}{*}{\multicolumn{2}{|c|}{$\begin{array}{c}\text { Constant } \\
\text { X1 }\end{array}$}} & $-3,647$ & \multicolumn{2}{|c|}{0,753} & \\
\hline & & 1,017 & & 221 & 1,12 \\
\hline \multicolumn{2}{|l|}{$\mathrm{X} 2$} & $-0,066$ & \multicolumn{2}{|c|}{0,338} & 1,21 \\
\hline \multicolumn{2}{|l|}{$\mathrm{X} 3$} & 0,292 & \multicolumn{2}{|c|}{0,340} & 1,33 \\
\hline
\end{tabular}

Berdasarkan tabel 2 dapat diketahui bahwa pada model tidak terdapat kasus multikolinearitas, hal ini ditunjukkan oleh nilai VIF semua variabel prediktor bernilai kurang dari 10. Langkah selanjutnya adalah mengetahui variabel yang signifikan terhadap model, variabel yang berpengaruh signifikan terhadap model yaitu dengan melihat nilainilai $p$-value kurang dari $\alpha(0,05)$ yaitu hanya variabel $\mathrm{X} 1$, sedangkan parameter yang memiliki nilai $p$-value lebih besar dari $\alpha$ adalah variabel X2 dan X3 dengan nilai $p$ value masing - masing sebesar 0,844 dan 0,404, sehingga variabel X2 dan X3 dikeluarkan dari model.

\section{Model Regresi Poisson}

Model regresi poisson untuk semua variabel penelitian setelah diuji : $\hat{\mu}=\exp \left(-3,647+1,017 X_{1}-0,066 X_{2}\right.$
$\left.+0,292 X_{3}\right)$

Dari model regresi poisson diatas dapat di interpretasikan bahwa nilai koefisien regresi poisson untuk variabel X2 adalah 0,066 dan koefisien pada variabel X3 adalah 0,292 tidak berpengaruh signifikan terhadap peluang lulus dibawah empat tahun di FMIPA Unsrat yang dapat dilihat pada tabel 3 bahwa $p$-value lebih besar dari nilai $\alpha$ $(0,05)$. 


\section{Model Regresi Poisson Terhadap Variabel Bebas Yang Signifikan}

Dalam penelitian ini setelah didapatkan hasil pada pengujian paramter variabel yang signifikan berpengaruh pada model dengan $\alpha$ sebesar 5\%, maka model terbaik untuk regresi poisson yaitu sebagai berikut :

$\hat{\mu}=\exp \left(-3,828+1,072 X_{1}\right)$

Variabel yang berpengaruh terhadap peluang lulus dibawah empat tahun di FMIPA Unsrat pada model regresi poisson yaitu IPK $(X 1)$, sedangkan pada variabel aktif berorganisasi (X2) dan mengikuti Olimpiade Nasional dan perwakilan Unsrat (X3) tidak berpengaruh signifikan yaitu dengan melihat nilai $P$-Value kurang dari $\alpha$ $(0,05)$ terhadap peluang lulus kurang dari empat tahun di Fmipa Unsrat.

Jadi, dapat disimpulkan bahwa variabel aktif berorganisasi $(X 2)$, mengikuti dan sebagai perwakilan Unsrat pada olimpiade nasional (X3) tidak berpengaruh signifikan terhadap peluang lulus dibawah empat tahun di Fmipa Unsrat dan untuk variabel IPK (X1) berpengaruh signifikan terhadap peluang lulus kurang dari empat tahun di FMIPA Unsrat.

Peluang untuk mahasiswa yang lulus kurang dari empat tahun di Fmipa Unsrat terhadap variabel yang signifikan IPK dapat dicari dengan rumus peluang regresi poisson yaitu :

$$
f\left(y_{i} \mid x_{i}\right)=\frac{e^{\mu_{i} \mu_{i} y_{i}}}{Y_{i} !}, \quad y_{i}=0,1,2 .
$$

Peluang lulus mahasiswa dengan masa studi kurang dari empat tahun di FMIPA Unsrat :

1. Mahasiswa yang memiliki IPK 3,00

$$
\begin{aligned}
& \mu_{i}=\exp (-3,828+1,072(3))=0,542 \\
& f(y=2 \mid 3,00)=\frac{e^{-0,542}(0,542)^{2}}{2 !}=0,085
\end{aligned}
$$

2 . Mahasiswa yang memiliki IPK 3,50

$$
\begin{aligned}
& \mu_{i}=\exp (-3,828+1,072(3,5))=0,927 \\
& f(y=2 \mid 3,50)=\frac{e^{-0,9927}(0,927)^{\mathrm{a}}}{2 !}=0,17
\end{aligned}
$$

3 . Mahasiswa yang memiliki IPK 4,00

$$
\begin{aligned}
& \mu_{i}=\exp (-3,828+1,072(4,00))=1,585 \\
& f(y=2 \mid 4,00)=\frac{e^{-1,585}(1,585)^{2}}{2 !}=0,01
\end{aligned}
$$

Peluang mahasiswa yang lulus kurang dari empat tahun pada FMIPA Unsrat pada tahun 2015-2018 yang memiliki IPK 3,00 sebesar 0,085, untuk mahasiswa yang memiliki IPK 3,5 sebesar 0,17 dan untuk mahasiswa yang memiliki IPK 4,00 sebesar 0,01 .

\section{KESIMPULAN DAN SARAN}

\section{Kesimpulan}

Faktor yang mempengaruhi peluang lulus dengan masa studi kurang dari empat tahun di FMIPA Unsrat secara signifikan adalah faktor IPK $\left(X_{1}\right)$. Model terbaik untuk regresi poisson yang didapatkan adalah, yaitu: $\hat{\mu}=\exp \left(-3,828+1,072 X_{1}\right)$.

\section{Saran}

1. Penelitian selanjutnya disarankan dapat dilakukan pada tingkat Universitas.

2. Sebaiknya dilakukan kajian kembali terhadap faktor-faktor lain yang diduga mempengaruhi lama studi mahasiswa jurusan di FMIPA Unsrat.

\section{DAFTAR PUSTAKA}

Agresti, A., 1990. Categorical Data Analysis, John Wiley and Sons, New York.

Cameron, A C and Trivedi, P K. 1998. Regression Analysis of Count Data. Cambridge University Press, Cambridge.

Dikti. 2017. Pangkalan Data Pendidikan Tinggi Kementrian Riset, Teknologi dan Pendidikan Tinggi. http://forlap.dikti.go.id/ [7 November 2018].

Hanifah dan Syukriy Abdullah. 2001. Pengaruh Perilaku Belajar Terhadap Prestasi Akademik Mahasiswa Akuntansi. Media Riset Akuntansi, Auditing, dan Informasi. Volume 1, No. 3, 63-86.

Hosmer, D.W. and S. Lemeshow, 2000. Applied Logistic Regression. Second Edition, John Willey \& Sons, New York.

Hogg, R. V. and Tanis, E. A. 1997. Probability and Statistical Inferene Sixth Edition. Prentice Hall Inc, New Jersey.

Kleinbaum, D G. 1988. Applied Regression Analysis and Other Multivariable Methods. PWS-KENT Publishing Company, USA city. 
Muhammad,Arni, 2007. Komunikasi Organisasi. Bumi Aksara, Jakarta.

Purhadi. 2013. Analisis Terhadap FaktorFaktor yang Mempengaruhi Laju Perbaikan Kondisi Klinis Pasien Penderita Stroke dengan Regresi Cox Weibull. Jurnal Sains dan Seni Promits. Vol. 2/No.1/2013: 23373520.

Peraturan Rektor UNSRAT No. 01/UN12/PP/2013 tentang Pedoman Penyelenggaraan Akademik di Universitas Sam Ratulangi.

Uyanto. 2009. Pedoman Analisis Data. Graha Ilmu, Yogyakarta .
Sutarto, 2006. Dasar-dasar Organisasi. Universitas Gajah Mada, Yogyakarta

Tiro, M.A. 2000. Analisis Regresi Dengan Data Kategori. Badan Penerbit Universitas Negeri Makassar, Makassar.

Undang-Undang Republik Indonesia Nomor 20 tahun 2003 Tentang Sistem Pendidikan Nasional.

Undang-Undang Republik Indonesia Nomor 12 Tahun 2012 Tentang Pendidikan Tinggi.

Walpole, R. E. 1995. Pengantar Statistik Edisi ke-3. Diterjemahkan oleh: Bambang Sumantri, Gramedia Pustaka Utama, Jakarta. 